\title{
The Effects of Curcumin on Wound Healing in a Rat Model of Nasal Mucosal Trauma
}

\author{
Gokhan Emiroglu, ${ }^{1}$ Zerrin Ozergin Coskun, ${ }^{1}$ Yildiray Kalkan, ${ }^{2}$ Ozlem Celebi Erdivanli, ${ }^{1}$ \\ Levent Tumkaya, ${ }^{2}$ Suat Terzi, ${ }^{1}$ Abdulkadir Özgür, ${ }^{1}$ Munir Demirci, ${ }^{1}$ and Engin Dursun ${ }^{1}$ \\ ${ }^{1}$ Department of Otorhinolaryngology, Recep Tayyip Erdogan University Medical Faculty, Rize, Turkey \\ ${ }^{2}$ Department of Histology and Embryology, Recep Tayyip Erdogan University Medical Faculty, Rize, Turkey
}

Correspondence should be addressed to Zerrin Ozergin Coskun; zerrinozergin@hotmail.com

Received 6 March 2017; Revised 7 June 2017; Accepted 9 July 2017; Published 5 September 2017

Academic Editor: Maria Camilla Bergonzi

\begin{abstract}
Copyright (C) 2017 Gokhan Emiroglu et al. This is an open access article distributed under the Creative Commons Attribution License, which permits unrestricted use, distribution, and reproduction in any medium, provided the original work is properly cited.
\end{abstract}

\begin{abstract}
We explored the effects of topical curcumin on the healing of nasal mucosal wounds. A total of 32 Sprague-Dawley Albino rats were randomized in equal numbers into four groups, and unilateral nasal wounds were created using an interdental brush. Group 1 (the sham-control group) contained untreated rats with traumatized right-side nasal cavities; Group 2 and 3 rats were similarly traumatized and treated with topical curcumin $(5$ and $10 \mathrm{mg} / \mathrm{mL})$ dissolved in dimethyl sulfoxide daily for 7 days after trauma; Group 4 rats were treated with topical dimethyl sulfoxide only. All rats were decapitated on day 15 and the healing sites evaluated by blinded observers in terms of the presence of cellular hyperplasia, goblet cell hypertrophy and degeneration, leucocytic infiltration, ciliary loss and degeneration, edema, and vascular dilation. On histopathological evaluation, all of cellular hyperplasia, leukocytic infiltration, and edema were significantly reduced in Group 3 compared with Group 1 ( $p=0.001, p=0.004$, and $p=0.008$, resp.). Thus, curcumin reduced the inflammatory response and significantly accelerated wound healing.
\end{abstract}

\section{Introduction}

Curcuma longa (turmeric) is a plant of the ginger family and has been used for many years in both India and China as both a spice and a traditional medicine. In India, turmeric has been widely used to treat biliary and hepatic diseases, coughs, diabetic ulcers, and rheumatic conditions. Curcumin is the most active form of the three different curcumoid extracts in the roots of plants [1]. Curcumin is insoluble in water but soluble in oil and ethanol. The chemical structure of curcumin (diferuloylmethane) was elucidated by Milobedska et al. in 1910. Curcumin has exerted antioxidant, antiaging, anti-inflammatory, immunomodulatory, wound healing, antitumoral, and antipsoriatic effects in various studies [1-3]. However, the effect of curcumin on nasal mucosal wounds has not yet been studied.

The nose is the first organ of the respiratory system, filtering, warming, and moistening inhaled air. The nose is also an olfactory organ and plays various roles in resonation, middle ear ventilation, drainage of the paranasal sinuses, sneezing, heat regulation, and the nasopulmonary reflexes. In such contexts, nasal mucosal health is key. The nasal respiratory mucosa is lined with ciliary, pseudostratified, columnar epithelial cells, and mucus-secreting goblet cells interspersed with ciliary cells [4].

Nasal mucosal wounding may develop after infection, accidents, and iatrogenically (septum/sinus surgeries). Wound healing after such injury is essential for maintenance of nasal ventilation and other functions. Wound healing is a complex process featuring a balance between inflammation, reepithelization, and matrix deposition; these processes are regulated by cytokines and growth factors released from leucocytes, fibroblasts, and epithelial cells [5]. Nasal mucosal trauma is associated with loss of goblet cells, thickening of the subepithelial layer (attributable to increased inflammation), neovascularization, and fibrosis. During healing, the numbers of goblet and ciliary cells, and the thickness of the subepithelial tissue, gradually approach those of healthy tissue [6].

In the present study, we histopathologically explored the effects of curcumin on wound healing of the nasal mucosa. 
TABle 1: The histopathological data $\left({ }^{+} p=0.001 ;{ }^{*} p=0.004 ;{ }^{\#} p=0.008\right)$.

\begin{tabular}{|c|c|c|c|c|c|c|}
\hline Group & $\begin{array}{c}\text { Cellular } \\
\text { hyperplasia }\end{array}$ & $\begin{array}{c}\text { Goblet cell } \\
\text { hypertrophy-degeneration }\end{array}$ & $\begin{array}{l}\text { Leucocyte } \\
\text { infiltration }\end{array}$ & $\begin{array}{l}\text { Loss of cilia and ciliary } \\
\text { cell degeneration }\end{array}$ & Edema & $\begin{array}{l}\text { Vascular } \\
\text { dilatation }\end{array}$ \\
\hline Group 1 & $3.00 \pm 0.46^{+}$ & $3.00 \pm 0.46$ & $4.00 \pm 0.35^{*}$ & $4.00 \pm 0.00$ & $3.00 \pm 0.35^{\neq}$ & $3.00 \pm 0.35$ \\
\hline Group 2 & $3.00 \pm 0.52$ & $4.00 \pm 0.52$ & $4.00 \pm 0.52$ & $3.00 \pm 0.46$ & $3.50 \pm 0.74$ & $3.00 \pm 0.64$ \\
\hline Group 3 & $2.00 \pm 0.35^{+}$ & $3.00 \pm 0.53$ & $3.00 \pm 0.53^{*}$ & $3.00 \pm 0.71$ & $2.00 \pm 0.52^{\neq}$ & $3.00 \pm 0.53$ \\
\hline Group 4 & $3.00 \pm 0.35$ & $3.00 \pm 0.53$ & $4.00 \pm 0.35$ & $4.00 \pm 0.00$ & $3.00 \pm 0.46$ & $3.00 \pm 0.53$ \\
\hline
\end{tabular}

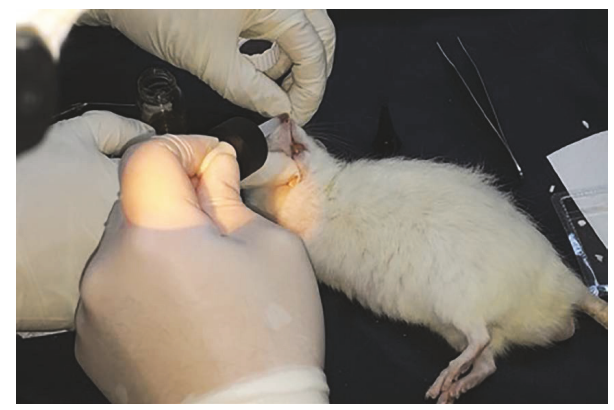

FIGURE 1: Application of drops to the right nasal cavity of the rat after traumatization.

\section{Materials and Methods}

The animal studies were approved by our Institutional Animal Care and Use Committee (approval number 2015-7).

2.1. Animals. We obtained 32 adult, male, 3-5-month-old Sprague-Dawley Albino (250-350 g) rats from our Institutional Animal Care Unit. After acclimation, the animals were divided into four groups and held in our experimental animal unit under a $12 \mathrm{~h} / 12 \mathrm{~h}$ light/dark cycle at $55-60 \%$ humidity and $22 \pm 3^{\circ} \mathrm{C}$. Ad libitum food and water were provided. The animals were always treated as mandated ones by the Helsinki Declaration. Nasal mucosal trauma was inflicted under anesthesia induced by intraperitoneal injection of ketamine hydrochloride (Alfamine ${ }^{\circledR}$, Alfasan International BV, Woerden, Holland) and xylazine $\mathrm{HCl}$ (Alfazyne ${ }^{\circledR}$, Alfasan) $(50 \mathrm{mg} / \mathrm{kg}$ and $10 \mathrm{mg} / \mathrm{kg}$, resp.).

2.2. Study Design. Mechanical injury was inflicted by inserting an interdental brush (10 $\mathrm{mm}$ in width) through the right nostril [6]; an absorbable gelatin sponge (Gelfoam ${ }^{\circledR}$; Pfizer Inc., New York, NY, USA) was then put in place (Figure 1). Group $1(n=8)$ was the sham-control group (no intervention). Groups $2(n=8)$ and $3(n=8)$ were the low- and high-curcumin groups, respectively. Rats in these groups received three drops daily of $5 \mathrm{mg} / \mathrm{mL}$ and $10 \mathrm{mg} / \mathrm{mL}$ solutions of curcumin (Sigma-Aldrich ${ }^{\circledR}$, St. Louis, MO, USA; catalog number: C1386) in dimethyl sulfoxide (DMS) (SigmaAldrich; catalog number D8418), for 7 days. Group $4(n=8)$ was the DMS-only group. All rats were decapitated on day 15 .

2.3. Histological Evaluation. Sections prepared from the traumatized regions of the nasal mucosa were stained with
Masson's trichrome dye (which reveals wound healing better than does hematoxylin-and-eosin staining). The slides were viewed under 20x and 40x magnification employing a light microscope. For each animal, five slides were randomly selected from the 10 slides containing the traumatized areas. All of cellular hyperplasia, goblet cell hypertrophy and degeneration, leukocytic infiltration, ciliary loss and degeneration, edema, and vascular dilatation were evaluated by two histologists blinded to group status. The histopathological results were graded as mild $(+)$, moderate $(++)$, severe $(+++)$, or very severe $(++++)$.

2.4. Statistical Analysis. Data were analyzed using the IBM Statistical Package for the Social Sciences ver. 16 (SPSS Inc., Chicago, IL, USA). Nonparametric tests (the Mann-Whitney $U$ test and the Kruskal-Wallis Test) were employed to compare normally distributed data. Continuous data are presented as means \pm standard deviations or as medians [minima-maxima], as appropriate. Bonferroni post hoc analysis was applied when multiple comparisons were performed. The original significance level ( $p$ value) of 0.05 was adjusted to $p<0.0083$ for individual comparisons when the Bonferroni correction was used.

\section{Results}

Group 1 (sham-control) rats exhibited goblet cell deformation, a reduction in goblet cell numbers, and mucus discharge from hypertrophic goblet cells (Figure 2). Vascular dilatation and perivascular edema were also evident. Pseudostratified columnar epithelial cells were absent from some areas. Diffuse ciliar desquamation of epithelial cells accompanied by areas of degeneration was observed; some cells both were pycnotic and had commenced apoptosis. Hyperplastic processes were evident, associated with patchy regions of epithelial condensation.

In Group 2 (the low-dose curcumin group), goblet cells were more numerous than in Group 1, but statistical significance was not attained (Table 1). The hypertrophic goblet cells lacked mucus. Compared with Group 1, the levels of epithelial cell desquamation and ciliary loss were reduced, and the extent of healing of degenerated areas increased, with borderline significance $(p=0.009)$. As in Group 1, some cells were pycnotic and some apoptotic. A few areas of vacuolization attributable to cell loss were observed (Figure 3). Groups 1 and 2 did not differ significantly in terms of hyperplasia, edema, vascular dilatation, or leukocytic infiltration $(p>$ 0.008). 


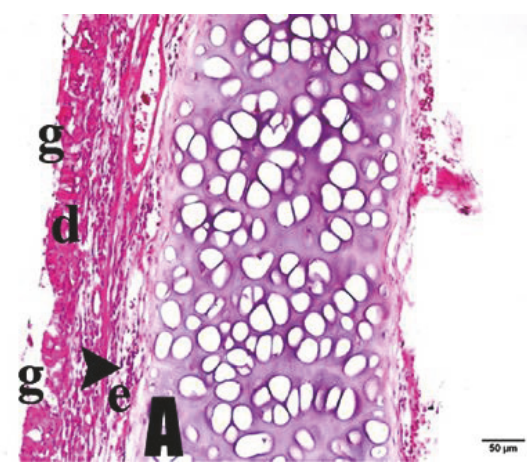

(a)

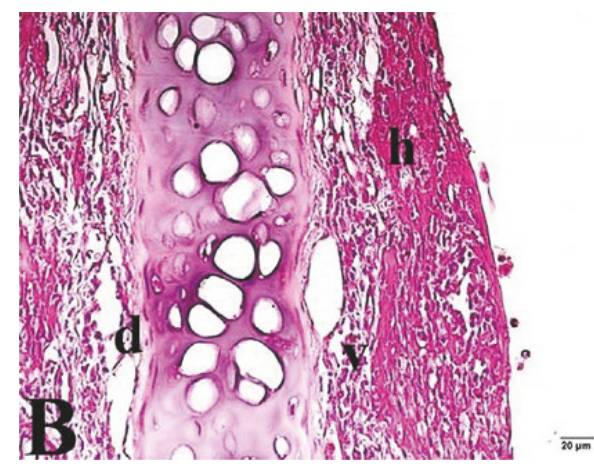

(b)

FIGURE 2: Nasal mucosa of Group 1 (sham-control group). (a) d: vascular dilatation; g: goblet cell; e: edema; arrowhead: leukocytic infiltration. (b) v: vacuolization; h: bleeding. Trichrome staining: (a) 20x and (b) 40x.

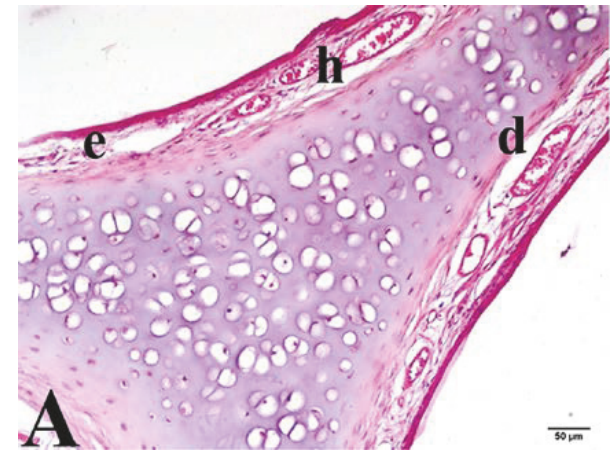

(a)

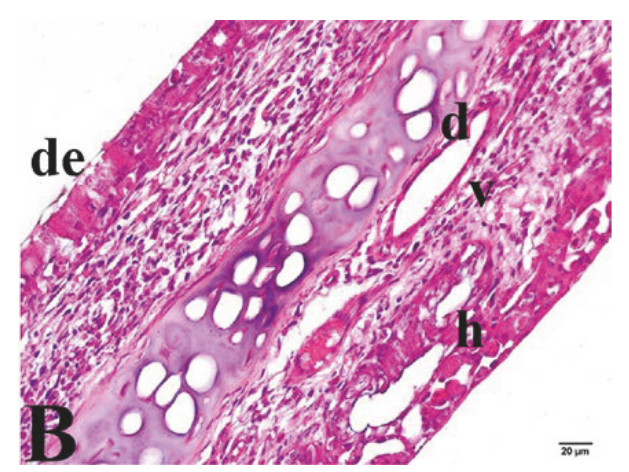

(b)

FIgURE 3: Nasal mucosa of Group 2 (low-dose curcumin group). (a) e: edema; h: bleeding; d: vascular dilatation. (b) h: bleeding; v: vacuolization; d: vascular dilatation; de: degenerative cell. Trichrome staining: (a) 20x and (b) 40x.

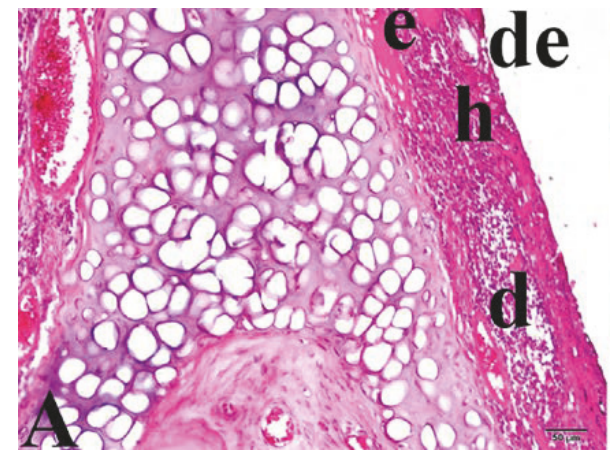

(a)

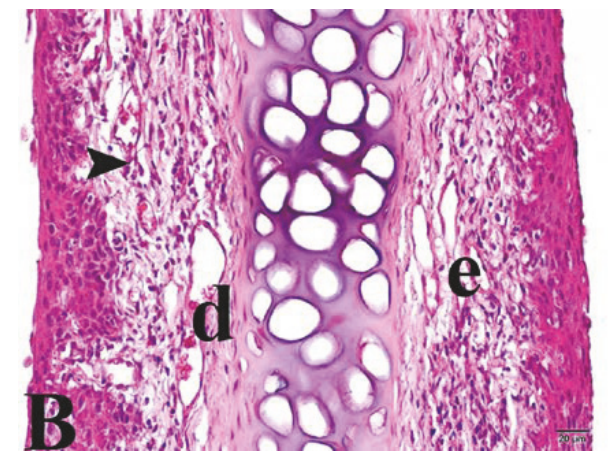

(b)

FIGURE 4: Nasal mucosa of Group 3 (high-dose curcumin group). (a) e: edema; h: bleeding; d: vascular dilatation; de: degenerative cell. (b) e: edema; d: vascular dilatation; arrowhead: leukocytic infiltration. Trichrome staining: (a) 20x and (b) 40x.

Compared with Group 1, Group 3 (the high-dose curcumin group) exhibited significant reductions in the extent of edematous mucosal areas, cellular hyperplasia, and leukocytic infiltration ( $p=0.008, p=0.001$, and $p=0.004$, resp.) (Figure 4), but the extent of vascular dilatation did not differ between the groups.
In Group 4 (the DMS group), the histopathological changes were similar to those of Group 1 (Figure 5). No significant between-group difference was evident in any of cellular hyperplasia, goblet cell hypertrophy or degeneration, leukocytic infiltration, ciliary loss or degeneration, edema, or vascular dilatation. 


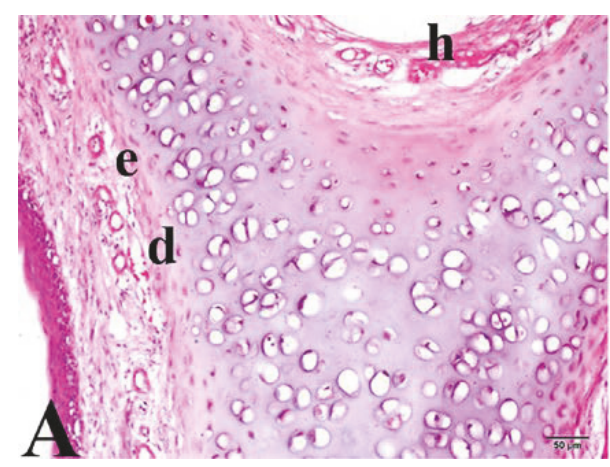

(a)

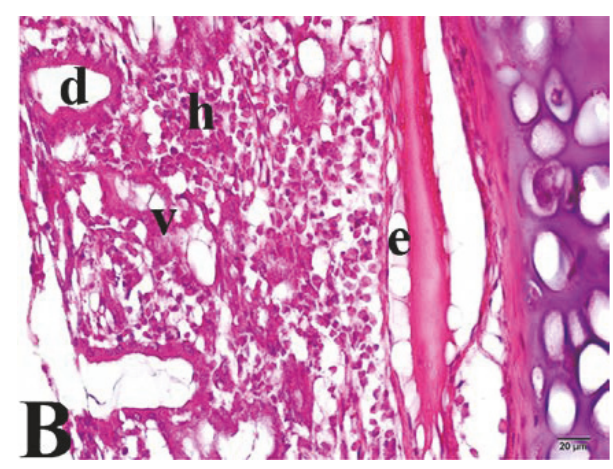

(b)

Figure 5: Nasal mucosa of Group 4 (DMS group). (a) e: edema; h: bleeding; d: dilatation. (b) e: edema; h: bleeding; v: vacuolization; d: vascular dilatation. Trichrome staining: (a) 20x and (b) 40x.

TABLE 2: Histopathological grades.

\begin{tabular}{|c|c|c|c|c|c|c|}
\hline Group & $\begin{array}{c}\text { Cellular } \\
\text { hyperplasia }\end{array}$ & $\begin{array}{c}\text { Goblet cell } \\
\text { hypertrophy/degeneration }\end{array}$ & $\begin{array}{l}\text { Leucocyte } \\
\text { infiltration }\end{array}$ & $\begin{array}{c}\text { Loss of cilia and ciliary } \\
\text { degeneration }\end{array}$ & Edema & $\begin{array}{l}\text { Vascular } \\
\text { dilatation }\end{array}$ \\
\hline 1 & +++ & +++ & ++++ & ++++ & +++ & +++ \\
\hline 2 & $++/+++$ & $+++/++++$ & $+++/++++$ & $+++/++++$ & $+++/++++$ & +++ \\
\hline 3 & ++ & +++ & +++ & $+++/++++$ & $++/+++$ & +++ \\
\hline 4 & +++ & +++ & ++++ & ++++ & +++ & +++ \\
\hline
\end{tabular}

+ : mild, ++ : moderate, +++ : severe, and ++++: very severe.

\section{Discussion}

Curcumin reduced the inflammatory response and accelerated wound healing in the nasal mucosa. Wound healing is a complex process with four interdependent phases: an early inflammatory phase (prominent within the first 2 days); a late inflammatory phase (commencing on day 2 or 3 after injury); a proliferative phase (days 4-21); and a remodeling phase (21 days to 1 year) [3, 7]. Edema and inflammation are associated with increases in vascular permeability, leukocytic infiltration, and extravasation of fluid from blood vessels to tissues. Wound repair is associated with normalization of vascular permeability, reduced leukocytic migration and edema, fibroblast proliferation, epithelial hyperplasia, enhanced regeneration, collagen deposition, and reduced ciliary cell loss and degeneration [6].

Lima et al. histopathologically studied the effects of trauma on the nasal mucosa; rats were sacrificed at 1 hour and $2,5,14$, and 28 days, after trauma. On light microscopy, significant increases were evident by day 2 in both woundedge edema and the subepithelial thickness index. By day 5 , reepithelization had commenced, characterized by the presence of undifferentiated epithelial cells and an edematous lamina propria wherein monocytes had replaced neutrophils. Although goblet cell numbers had increased by day 14, irregularities in both goblet and ciliary cells, and epithelial layer thickening, persisted. By day 28, the respiratory mucosa had regained its normal structural anatomy [3].

Although the effects of curcumin on various tissues have been studied, its effect on wound healing of the nasal mucosa has not been examined to date. Both Groups 2 and 3 exhibited significant cellular regeneration and reductions in cell loss from the respiratory epithelial layer and near-significant reductions in ciliary loss and degeneration $(p=0.009 ; p=$ $0.01)$.

Topical curcumin $(10 \mathrm{mg} / \mathrm{mL})$ significantly reduced edema, cellular hyperplasia, and leukocytic infiltration compared with the sham-control group $(p=0.008, p=$ 0.001 , and $p=0.004$, resp.). However, such changes were not observed in Group 2 (the $5 \mathrm{mg} / \mathrm{mL}$ curcumin group). Thus, high-dose topical curcumin is required to exert an antiinflammatory effect. Treatment with $10 \mathrm{mg} / \mathrm{mL}$ curcumin reduced cellular hyperplasia to the normal level and accelerated wound healing (Table 2).

Curcumin exerts anti-inflammatory, anti-infectious, and antioxidant effects [8-11], inhibiting the production of two cytokines (IL-1 and TNF- $\alpha$ ) that activate the monocytes and macrophages playing important roles in regulation of the inflammatory response [12]. Curcumin inhibits the action of transcription factor NF- $(\kappa) \mathrm{B}$ (nuclear factor kappa-lightchain-enhancer of activated B cells) [13]. One of the primary physiological roles of nuclear factor, $\mathrm{NF}-(\kappa) \mathrm{B}$, is in the immune system. In particular, $\mathrm{NF}-(\kappa) \mathrm{B}$ family members control the transcription of cytokines that regulate cellular differentiation, survival, and proliferation. In addition, NF$(\kappa) \mathrm{B}$ also contributes to the development and survival of the cells and tissues that carry out immune responses in mammals [14].

Joe et al. showed that application of curcumin-loaded polymeric bandages to rats significantly reduced antioxidant 
enzyme expression, attributable to the fact that curcumin reduced lipid peroxidation and thus lowered the requirement for antioxidant enzymes [13]. The level of high-aldehyde collagen also increased. Panchatcharam et al. observed both an increase in collagen level and earlier maturation of collagen fibers [8].

In a diabetic rat model, topical application of curcumin to wounds improved the organization of granulation tissue and was associated with higher numbers of myofibroblasts and smaller capillaries [15]. However, in our study, curcumin did not reduce vascular dilatation; curcumin may promote both neovascularization and small capillary formation.

Curcumin exerts an apoptotic effect early in wound healing. In rats bearing curcumin-containing bandages, early cell death (DNA fragmentation) was apparent 4 days after treatment [13]. Akbik et al. showed that, during wound healing, curcumin prolonged the inflammatory phase only minimally and accelerated the proliferation phase [1], which generally commences 4 to 21 days after injury. However, the phases of wound healing are often superimposed. Reepithelization (part of the proliferative phase) probably commences immediately after trauma [3].

Joe et al. showed that, in a control group, apoptosis increased 11 days after injury, but all early apoptotic cells had been eliminated in the curcumin-treated group by this time, showing that the untreated group was in the early phase of wound healing but the curcumin-treated group was in the proliferative phase [13].

In the rat, curcumin facilitated complete wound reepithelization, reducing the epithelization period from 23 to 11 days compared with a control group [12]. In our study, 15 days of high-dose curcumin treatment was associated with reduced ciliary degeneration and loss and less cellular hyperplasia, compared with the sham-control group, and the respiratory epithelium became normalized. Thus, curcumin accelerated epithelization of the wound site.

Curcumin is insoluble in water but soluble in oil and alcohol. Thus, curcumin is poorly absorbed and is present in serum only in a compound form. Curcumin is extensively first-pass metabolized and is sensitive to light [16]. Many studies have shown that topical application of curcumin to wound sites was more effective than oral intake, affording higher local concentrations [16, 17].

DMS (used to dissolve curcumin) is a valuable organic sulfurous solvent derived from wood. DMS is transported from the skin or even the nails into the body and enhances the absorption of dissolved materials [18, 19]. We used a curcumin/DMS solution for topical application; DMS alone did not affect wound site healing. Some studies have evaluated curcumin nanoformulations. Such curcumin preparations (small particles of high surface area) exhibited enhanced intracellular penetration $[20,21]$. The nanoparticles penetrated cancer cells to a greater extent than did simpler preparations and reduced cell proliferation [20]. Also, nanoformulated curcumin exhibits good bioavailability and a long half-life and can be effectively dispersed in water [21]. Thus, aqueous curcumin creams may be prepared.

A limitation of our study is the lack of electron microscopic histopathological data (our institutional resources are limited). However, significant healing improvements were readily evident under a light microscope. Curcumin notably accelerated wound healing and can thus be used to treat nasal mucosal injuries persisting after nasal trauma, septoplasty, turbinate surgery, functional endoscopic sinus surgery, and tumor removal. The optimal dose level and interval, and the maximum tolerated dose, remain to be determined. Also, alternative delivery mechanisms deserve attention.

\section{Disclosure}

This paper was presented as oral presentation at 12th Turkish Rhinology Congress, April 2016, Antalya, Turkey.

\section{Conflicts of Interest}

The authors declare that they have no conflicts of interest.

\section{Authors' Contributions}

Gokhan Emiroglu conceived the work, analyzed the data, drafted the article, approved the final text, and accepts responsibility for the integrity of the research. Zerrin Ozergin Coskun designed the work, analyzed the data, drafted the article, approved the final text, and is accountable for the integrity of the work. Yildiray Kalkan acquired data, drafted the article, approved the final text, and is accountable for the integrity of the work. Ozlem Celebi Erdivanli interpreted the data, drafted the article, approved the final text, and is accountable for the integrity of the work. Levent Tumkaya interpreted the data, drafted the article, approved the final text, and is accountable for the integrity of the work. Suat Terzi analyzed data, drafted the article, approved the final text, and is accountable for the integrity of the work. Abdulkadir Özgür designed the work, interpreted the data, revised the article, approved the final text, and is accountable for the integrity of the work. Munir Demirci gathered data, revised the article, approved the final text, and is accountable for the integrity of the work. Engin Dursun interpreted data, revised the article, approved the final text, and is accountable for the integrity of the work.

\section{References}

[1] D. Akbik, M. Ghadiri, W. Chrzanowski, and R. Rohanizadeh, "Curcumin as a wound healing agent," Life Sciences, vol. 116, no. 1, pp. 1-7, 2014

[2] D. K. Agrawal and P. K. Mishra, "Curcumin and its analogues: potential anticancer agents," Medicinal Research Reviews, vol. 30, no. 5, pp. 818-860, 2010.

[3] C. F. Lima, C. Pereira-Wilson, and S. I. S. Rattan, "Curcumin induces heme oxygenase-1 in normal human skin fibroblasts through redox signaling: relevance for anti-aging intervention," Molecular Nutrition and Food Research, vol. 55, no. 3, pp. 430442, 2011.

[4] Z. K. Gencer, L. Saydam, N. A. Cohen, and C. Cingi, "Nacetylcysteine effects on sinonasal cilia function," ENT Updates, vol. 5, no. 3, pp. 87-92, 2015.

[5] J. B. Watelet, P. Demetter, C. Claeys, P. Van Cauwenberge, C. Cuvelier, and C. Bachert, "Wound healing after paranasal sinus 
surgery: neutrophilic inflammation influences the outcome," Histopathology, vol. 48, no. 2, pp. 174-181, 2006.

[6] R. Khalmuratova, S.-Y. Jeon, D. W. Kim et al., "Wound healing of nasal mucosa in a rat," American Journal of Rhinology and Allergy, vol. 23, no. 6, pp. e33-e37, 2009.

[7] L. Birdane, T. San, N. B. Muluk, D. Burukoglu, and C. Cingi, "Efficacy of Curcumin in the healing of paracentesis in rats," International Journal of Pediatric Otorhinolaryngology, vol. 78, no. 2, pp. 280-284, 2014.

[8] M. Panchatcharam, S. Miriyala, V. S. Gayathri, and L. Suguna, "Curcumin improves wound healing by modulating collagen and decreasing reactive oxygen species," Molecular and Cellular Biochemistry, vol. 290, no. 1-2, pp. 87-96, 2006.

[9] G. C. Jagetia and G. K. Rajanikant, "Acceleration of wound repair by curcumin in the excision wound of mice exposed to different doses of fractionated gamma radiation," International Wound Journal, vol. 9, no. 1, pp. 76-92, 2012.

[10] M. Akpolat, M. Kanter, and M. C. Uzal, "Protective effects of curcumin against gamma radiation-induced ileal mucosal damage," Archives of Toxicology, vol. 83, no. 6, pp. 609-617, 2009.

[11] R. L. Thangapazham, S. Sharad, and R. K. Maheshwari, "Skin regenerative potentials of curcumin," BioFactors, vol. 39, no. 1, pp. 141-149, 2013.

[12] T.-T. Phan, P. See, S.-T. Lee, and S.-Y. Chan, "Protective effects of curcumin against oxidative damage on skin cells in vitro: its implication for wound healing," Journal of Trauma - Injury, Infection and Critical Care, vol. 51, no. 5, pp. 927-931, 2001.

[13] B. Joe, M. Vijaykumar, and B. R. Lokesh, "Biological properties of curcumin-cellular and molecular mechanisms of action," Critical Reviews in Food Science and Nutrition, vol. 44, no. 2, pp. 97-111, 2004.

[14] M. S. Hayden, A. P. West, and S. Ghosh, "NF- $\kappa$ B and the immune response," Oncogene, vol. 25, no. 51, pp. 6758-6780, 2006.

[15] Z. Qian, M. Dai, X. Zheng et al., "Chitosan-alginate sponge: preparation and application in curcumin delivery for dermal wound healing in rat," Journal of Biomedicine and Biotechnology, vol. 2009, Article ID 595126, 8 pages, 2009.

[16] P. Anand, A. B. Kunnumakkara, R. A. Newman, and B. B. Aggarwal, "Bioavailability of curcumin: problems and promises," Molecular Pharmaceutics, vol. 4, no. 6, pp. 807-818, 2007.

[17] S. Wang, M. Tan, Z. Zhong, M. Chen, and Y. Wang, "Nanotechnologies for curcumin: an ancient puzzler meets modern solutions," Journal of Nanomaterials, vol. 2011, Article ID 723178, 2011.

[18] A. A. Gurtovenko and J. Anwar, "Modulating the structure and properties of cell membranes: the molecular mechanism of action of dimethyl sulfoxide," Journal of Physical Chemistry B, vol. 111, no. 35, pp. 10453-10460, 2007.

[19] K. Capriotti and J. A. Capriotti, "Onychomycosis treated with a dilute povidone-iodine/dimethyl sulfoxide preparation," International Medical Case Reports Journal, vol. 8, pp. 231-233, 2015.

[20] W.-H. Lee, C.-Y. Loo, P. M. Young, D. Traini, R. S. Mason, and R. Rohanizadeh, "Recent advances in curcumin nanoformulation for cancer therapy," Expert Opinion on Drug Delivery, vol. 11, no. 8, pp. 1183-1201, 2014.

[21] W.-H. Lee, M. Bebawy, C.-Y. Loo, F. Luk, R. S. Mason, and R. Rohanizadeh, "Fabrication of curcumin micellar nanoparticles with enhanced anti-cancer activity," Journal of Biomedical Nanotechnology, vol. 11, no. 6, pp. 1093-1105, 2015. 


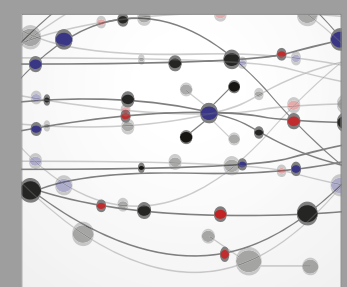

The Scientific World Journal
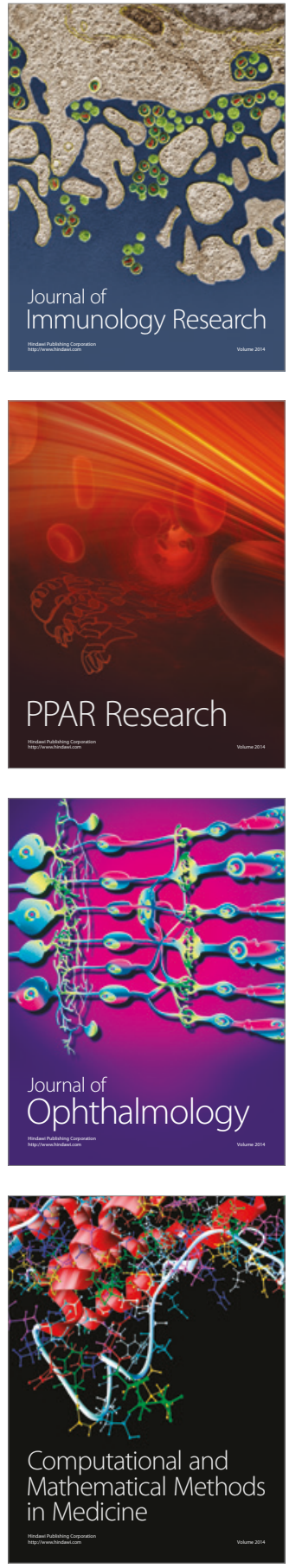

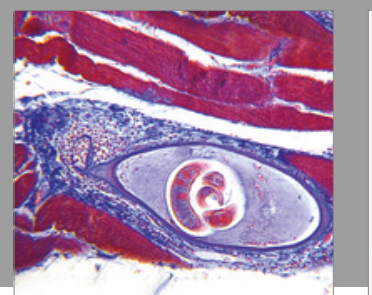

Gastroenterology Research and Practice
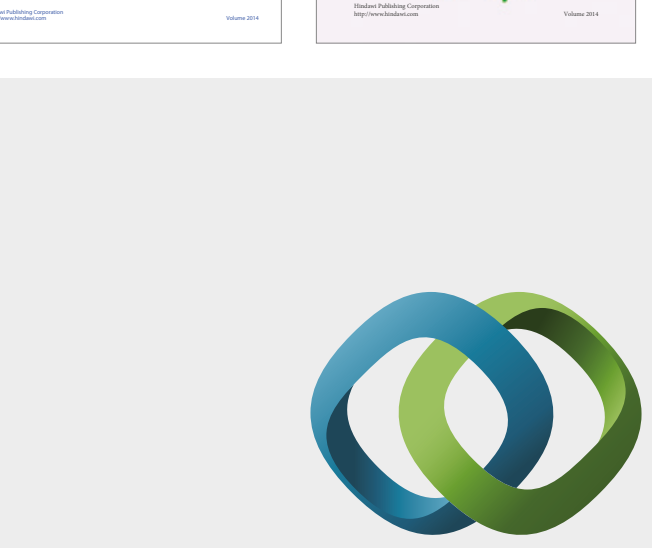

\section{Hindawi}

Submit your manuscripts at

https://www.hindawi.com
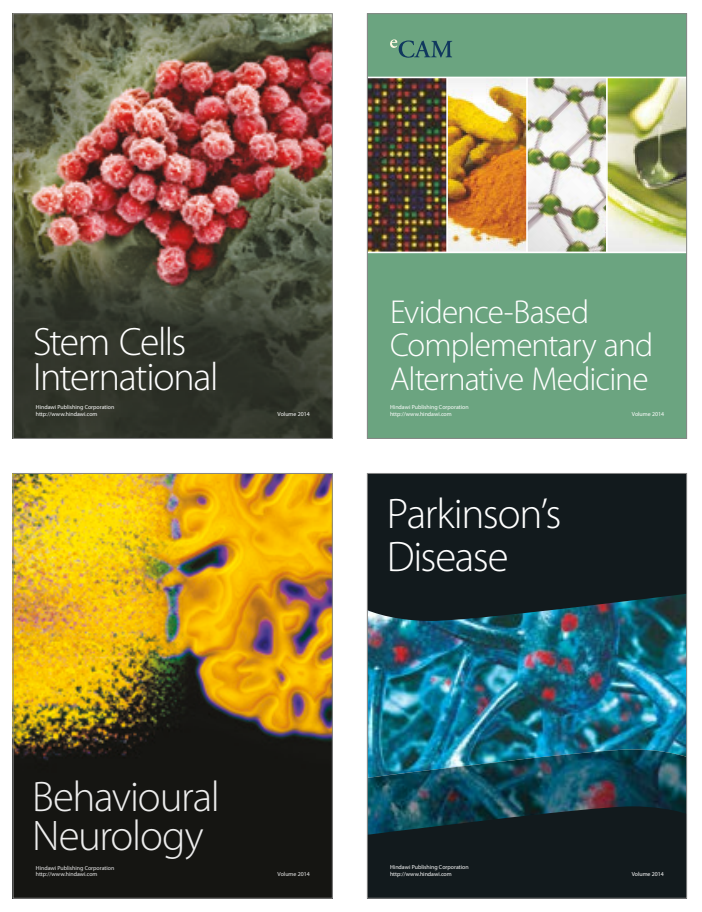
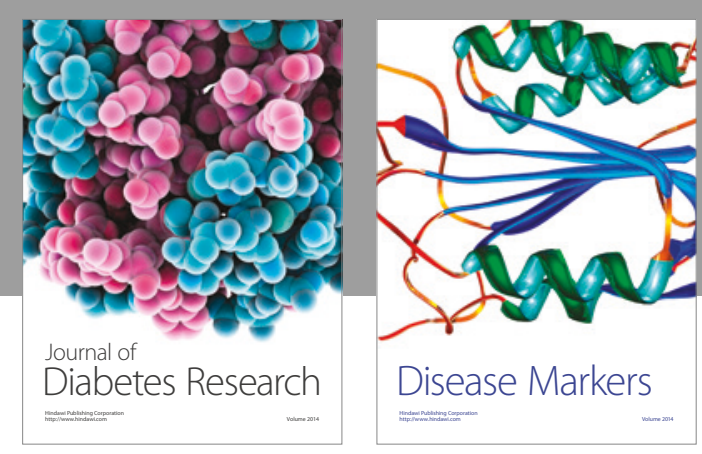

Disease Markers
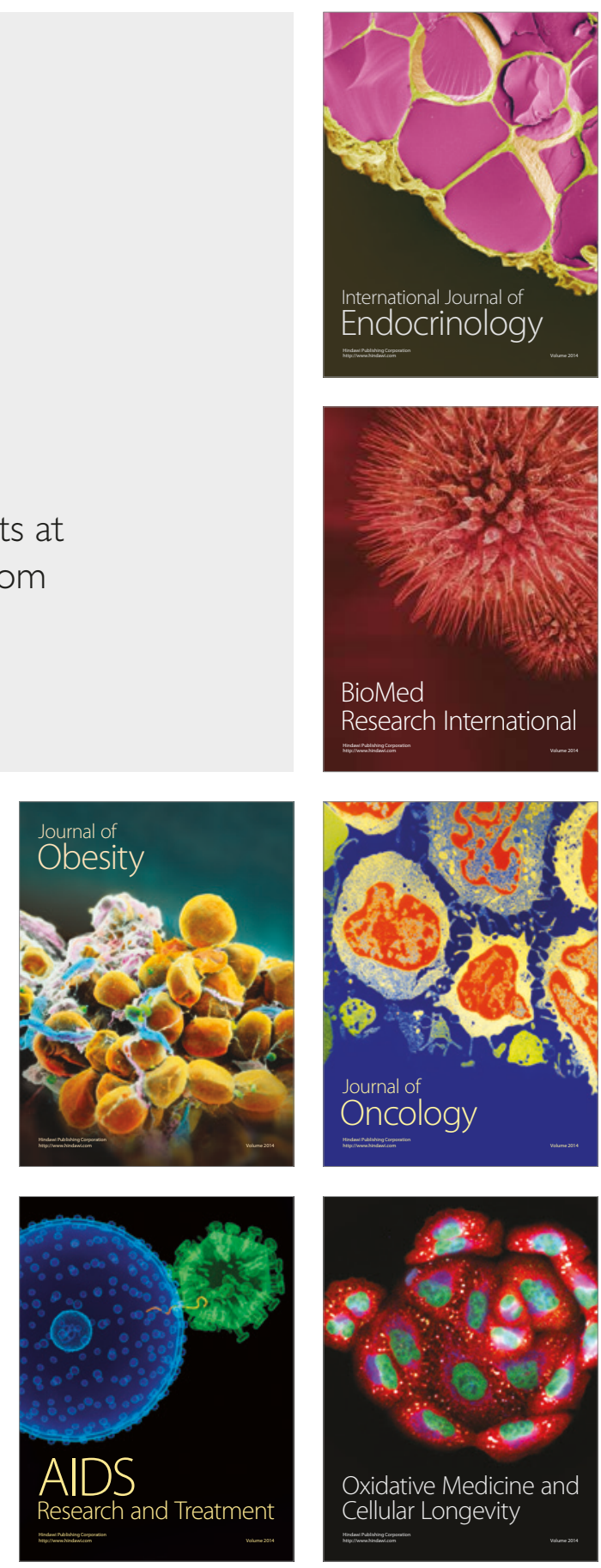